\title{
The influence of moderate red wine consumption on antioxidant status and indices of oxidative stress associated with CHD in healthy volunteers
}

\author{
Catherine Tsang ${ }^{1}$, Siobhan Higgins ${ }^{2}$, Garry G. Duthie ${ }^{3}$, Susan J. Duthie ${ }^{3}$, Moira Howie ${ }^{4} \dagger$, \\ William Mullen ${ }^{1}$, Michael E. J. Lean ${ }^{5}$ and Alan Crozier ${ }^{1 *}$ \\ ${ }^{1}$ Plant Products and Human Nutrition Group, Division of Biochemistry and Molecular Biology, University of Glasgow, \\ Glasgow G12 8QQ, UK \\ ${ }^{2}$ Department of Human Nutrition, University of Glasgow, Yorkhill Hospitals, Glasgow G3 8SJ, UK \\ ${ }^{3}$ Rowett Research Institute, Greenburn Road, Bucksburn, Aberdeen AB21 9SB, UK \\ ${ }^{4}$ Safeway Stores plc, 6 Millington Road, Hayes, Middlesex, UB3 4AY, UK \\ ${ }^{5}$ Department of Human Nutrition, University of Glasgow, Queen Elizabeth Building, Royal Infirmary, Glasgow G23 2ER, UK
}

(Received 20 April 2004 - Revised 24 September 2004 - Accepted 26 September 2004)

\begin{abstract}
The effects of moderate red wine consumption on the antioxidant status and indices of lipid peroxidation and oxidative stress associated with CHD were investigated. A randomised, controlled study was performed with twenty free-living healthy volunteers. Subjects in the red wine group consumed $375 \mathrm{ml}$ red wine daily for 2 weeks. We measured the total concentration of phenolics and analysed the individual phenolics in the wine and plasma by HPLC with tandem MS. The antioxidant capacity of plasma was measured with electron spin resonance spectroscopy while homocysteine and fasting plasma lipids were also determined. The production of conjugated dienes and thiobarbituric acid-reactive substances (TBARS) were measured in Cu-oxidised LDL. Plasma total phenolic concentrations increased significantly after 2 weeks of daily red wine consumption $(P \leq 0.001)$ and trace levels of metabolites, mainly glucuronides and methyl glucuronides of $(+)$-catechin and (-)-epicatechin, were detected in the plasma of the red wine group. These flavan-3-ol metabolites were not detected in plasma from the control group. The maximum concentrations of conjugated dienes and TBARS in Cu-oxidised LDL were reduced $(P \leq 0 \cdot 05)$ and HDL cholesterol concentrations increased $(P \leq 0 \cdot 05)$ following red wine consumption. The findings from the present study provide some evidence for potential protective effects of moderate consumption of red wine in healthy volunteers.
\end{abstract}

Red wine: Phenolics: Conjugated dienes: Thiobarbituric acid-reactive substances

There is much public, media and scientific interest in the possibility that red wine may be protective against CHD. Mounting evidence suggests that moderate red wine consumption is inversely associated with $\mathrm{CHD}$, an association popularised as the 'French paradox' (Renaud \& De Logeril, 1993). The paradox describes the seemingly low mortality rates among certain populations in France despite high levels of associated risk factors: serum cholesterol, systolic blood pressure, dietary fat intakes and low consumption of fruits and vegetables. It is speculated that this paradox is associated with the widespread consumption of red wine (Criqui \& Ringel, 1994). Although there is evidence to suggest that a light to moderate intake of alcohol is beneficial to health (Albert et al. 1999), it has been shown that red wine provides additional health benefits beyond those of alcohol alone (Rimm et al. 1996; Burns et al. 2001a).

The putative cardio-protective effects of red wine have largely been attributed to the abundance of phenolic compounds. Plant-derived phenolics are widely distributed in nature and are present in varying amounts in commonly consumed fruits, vegetables and beverages (Duthie \& Crozier, 2003; Saltmarsh et al. 2003). Red wine provides an especially rich source of these compounds, which originate from grape seeds, skins and vine stems (Singleton, 1982). The levels of phenolic acids, major catechins and anthocyanins in red wine vary depending on the grape variety and vintage (Landrault et al. 2001), as well as on climate and vinification practices (Goldberg et al. 1998; Burns et al. 2001b). Generally, red wines contain between 1000 and $4000 \mathrm{mg}$ phenolics/l, the majority of which are derived from anthocyanins and proanthocyanidins (Burns et al. 2000).

Although the exact mechanisms of the protection conferred by red wine are unknown, there is evidence that phenolic compounds act as antioxidants by protecting the body from damaging oxidation reactions caused by free radicals (Kanner et al. 1994). There is further evidence that they

\footnotetext{
Abbreviation: TBARS, thiobarbituric acid-reactive substances.

* Corresponding author: Professor A. Crozier, fax +44 141330 5394, email a.crozier@bio.gla.ac.uk

$\dagger$ Present address: Waitrose, Bracknell, Berkshire, RG12 8YA, UK.
} 
may inhibit oxidative modification of LDL based on their ability to increase the resistance of isolated LDL to $\mathrm{Cu}$ oxidation in vitro (Frankel et al. 1995). Several studies have demonstrated that many dietary phenolics protect against the oxidative modification of LDL in vitro (Vinson \& Hontz, 1995; Teissedre et al. 1996). Despite increasing evidence for the in vitro effectiveness of phenolics, there remains a dearth of information regarding their efficacy in vivo and this may be due, in part, to a lack of knowledge on their bioavailability in man. The results from wine trials to date have presented conflicting results, with some showing a protective effect following red wine intake (Serafini et al. 1998; Natella et al. 2001) while others have not demonstrated such an effect (van Golde et al. 1999).

The present paper reports the results of an intervention study in which the influence of red wine consumption on the antioxidant status and on indices of oxidative stress associated with CHD was investigated in healthy volunteers.

\section{Methods}

\section{Study design}

A randomised, controlled study was performed with twenty free-living healthy volunteers. Subjects were non-smokers, aged between 23 and 50 years, who were not taking medications or vitamin supplements. The study protocol was approved by the Research Ethics Committee, Glasgow Royal Infirmary, UK. Written informed consent was obtained from each volunteer. Subjects were randomised into two groups: red wine; control. Volunteers were required to avoid all alcohol and foods/beverages rich in polyphenols, and to limit fruit and vegetable intake over the study period. Subjects in the red wine group were asked to consume $375 \mathrm{ml}$ red wine (1999 Bulgarian Young Vatted Cabernet Sauvignon, $12 \%$ alcohol Safeway, Hayes, UK) each day for 2 weeks. Fasting blood samples obtained at weekly intervals were collected into EDTA and lithium heparin tubes. Plasma was immediately separated by low-speed centrifugation $(2500 \mathrm{~g}$ for $10 \mathrm{~min}$ at $4^{\circ} \mathrm{C}$ ) and stored at $-80^{\circ} \mathrm{C}$ prior to analysis. For vitamin $\mathrm{C}$ analysis, $0.6 \mathrm{ml}$ plasma was mixed with an equal volume of $10 \%$ (w/v) meta-phosphoric acid, snapfrozen in liquid $\mathrm{N}$ and stored at $-80^{\circ} \mathrm{C}$ prior to analysis. Subjects were required to record food and beverage intake over the study period and this information was used to assess compliance with the dietary instructions given.

\section{Measurement of plasma carotenoids, tocopherols and retinol}

The levels of six carotenoids (lutein/zeaxanthin, $\beta$-cryptoxanthin, lycopene, $\alpha$-carotene and $\beta$-carotene), retinol and $\alpha$ - and $\gamma$-tocopherol in plasma were measured by reversedphase HPLC with absorbance and fluorimetric detection according to the method of Hess et al. (1991). The analysis was conducted under the auspices of the US National Institute of Standards Quality Assurance Scheme for fatsoluble vitamins; full details of the method are given in Duthie (1999).

\section{Determination of ascorbic acid}

Ascorbic acid content was determined from $0.6 \mathrm{ml}$ plasma and measured by ion-pair reversed-phase HPLC with UV detection (Ross, 1994). Analysis was conducted under the US National Institute of Standards Quality Assurance Scheme for vitamin $\mathrm{C}$ analysis in biological fluids and the method is described in detail in Duthie (1999).

\section{Plasma antioxidant capacity}

Antioxidant capacity of plasma was measured using electron spin resonance spectroscopy as described by Gardner et al. (1998). This assay is based on the ability of antioxidants in plasma to donate a hydrogen atom or electron to the synthetic free radical, potassium nitrodisulphonate (Fremy's salt).

\section{Total phenolic concentrations}

Total phenolics were measured in red wine using the Folin-Ciocalteau method (Singleton \& Rossi, 1965) with data expressed as gallic acid equivalents. Total phenols in plasma were also estimated with Folin-Ciocalteu reagent using a modification of the method of Swaine \& Hillis (1959), which avoids interference from proteins in biological samples (Serafini et al. 1998).

\section{Determination of conjugated dienes and thiobarbituric acid-reactive substances}

LDL was isolated from plasma by density-gradient ultracentrifugation at $35000 \mathrm{rpm}$ for $15 \mathrm{~h}$ at $15^{\circ} \mathrm{C}$. The LDL fraction was removed and samples were dialysed at $4^{\circ} \mathrm{C}$ against 40 litres PBS containing $10 \mu \mathrm{M}-\mathrm{Na}_{2}$ EDTA $(\mathrm{pH} \mathrm{7.4)}$ for $42 \mathrm{~h}$ while shaking gently in a microdialysis unit (GibcoBRL, Life Technologies Ltd, Paisley, UK). The protein concentration of dialysed LDL was analysed according to the method of Markwell et al. (1981). Samples were adjusted to a concentration of $50 \mu \mathrm{g}$ LDL protein $/ \mathrm{ml}$ and $1 \mu \mathrm{M}-$ EDTA in quartz cuvettes. Oxidation of LDL was initiated by addition of $15 \mu \mathrm{M}-\mathrm{CuSO}_{4}$ (Kleinveld et al. 1992). Absorbance of the samples was measured at $234 \mathrm{~nm}$, every 2 min at $30^{\circ} \mathrm{C}$. Maximal oxidation rate $(\mathrm{nmol} / \mathrm{mg} \mathrm{LDL}$ protein per min), maximal diene concentration ( $\mathrm{nmol} / \mathrm{mg}$ LDL protein) and lag phase ( $\mathrm{min}$ ) were estimated using exact coordinates provided by the kinetics software application (Beckman Instruments Inc., Fullerton, CA, USA).

LDL that was oxidised for measurement of conjugated dienes was subsequently used for the measurement of thiobarbituric acid-reactive substances (TBARS; Buege \& Aust, 1978). Following oxidation for $3 \mathrm{~h}$, the reaction was stopped by addition of $200 \mu \mathrm{M}$-EDTA and $40 \mu \mathrm{M}-$ butylated hydroxytoluene and the samples stored at $4{ }^{\circ} \mathrm{C}$ for a maximum of $7 \mathrm{~d}$. TBARS were determined by adding $1.6 \mathrm{ml}$ TCA-TBA- $\mathrm{HCl}$ reagent $(15 \%$ trichloroacetic acid $-0.375 \%$ thiobarbituric acid $-0.25 \mathrm{~mol} \mathrm{HCl})$ to a $0.8 \mathrm{ml}$ aliquot of the LDL solution (oxidised as above), mixing the sample and then heating it in boiling water at $100^{\circ} \mathrm{C}$ for $15 \mathrm{~min}$. After placing the tubes in a bath of cold water for $5 \mathrm{~min}$, samples were centrifuged for $10 \mathrm{~min}$ at $2000 \mathrm{rpm}$. Absorbance was measured at $535 \mathrm{~nm}$ 
and quantification of TBARS was performed by comparison with a standard curve of malonaldehyde equivalents generated by acid-catalysed hydrolysis of 1,1,3,3-tetraethoxypropane (Sigma Chemical Co., Poole, Dorset, UK).

\section{Homocysteine concentrations}

Plasma homocysteine $(200 \mu \mathrm{l})$ was measured using a DS30 Hcy homocysteine assay kit and a DS30 analyser (Drew Scientific Ltd, Barrow-in-Furness, Cumbria, UK) according to the method of Duthie et al. (2002). Quantitative evaluation of the homocysteine concentration was achieved by comparison with a two-point calibration.

\section{Fasting plasma lipids}

Fasting plasma lipids including total cholesterol, HDL cholesterol, LDL cholesterol and triacylglycerol concentrations were determined using an automated Hitatchi 197 multichannel analyser (Roche Diagnostics, Lewes, East Sussex, UK) using standard procedures. LDL cholesterol concentrations were calculated using the Friedewald formula (Friedewald et al. 1972).

\section{Extraction and measurement of phenolics in plasma}

Plasma was extracted according to a modified method of Day et al. (2001). Briefly, $1.5 \mathrm{ml}$ acetonitrile was added to $0.5 \mathrm{ml}$ stabilised plasma. Samples were vortexed for $30 \mathrm{~s}$ every $2 \mathrm{~min}$ over a $10 \mathrm{~min}$ period, before centrifugation at $4000 \mathrm{~g}$ for $20 \mathrm{~min}$. The supernatant was removed and the pellet was further extracted with $1.5 \mathrm{ml}$ methanol, then the process was repeated again as described. The two supernatants were mixed and dried in a centrifugal vacuum concentrator at $38^{\circ} \mathrm{C}$. Four hundred and fifty $\mu \mathrm{l}$ $1 \%$ formic acid in $50 \mu \mathrm{l}$ methanol was added to the dried pellet, centrifuged at $25000 \mathrm{~g}$ for $10 \mathrm{~min}$ and analysed by HPLC with tandem MS.

\section{HPLC with tandem MS}

Wine and plasma $(100 \mu \mathrm{l})$, extracted as earlier, at baseline and after 2 weeks in the red wine and control group, was injected and analysed on a Surveyor HPLC system comprising an HPLC pump, a diode array detector scanning from 250 to $700 \mathrm{~nm}$ and an auto sampler set at $4^{\circ} \mathrm{C}$ (Thermo Finnigan, San Jose, CA, USA). Separation was carried out using a $250 \mathrm{~mm} \times 4.6 \mathrm{~mm}$ (inner diameter) $4 \mu \mathrm{m}$ Synergi RP-Max column (Phenomenex, Macclesfield, Cheshire, UK) eluted at a flow rate of $1 \mathrm{ml} / \mathrm{min}$. A 5-40\% gradient over $60 \mathrm{~min}$ of $0.1 \%$ formic acid and acetonitrile was used for the complete separation of all compounds. After passing through the flow cell of the diode array detector, the column eluate was split and $0.3 \mathrm{ml}$ was directed to an LCQ Deca XP ion-trap mass spectrometer fitted with an electrospray interface (Thermo Finnigan). Analysis was carried out in full-scan mode from 100 to 2000 amu using the positive-ion mode when analysing anthocyanins and with negative ionisation for all other compounds. Selective reaction monitoring was additionally used to detect selected ions in the plasma.

\section{Statistical analysis}

Mean values and standard errors were calculated for all measurements. Analysis of the significance of the differences observed between measurements within the same group before and after the intervention was done by the paired $t$ test. A two-sample $t$ test for independent analysis of samples was used to compare between the values obtained from the intervention and control groups at baseline and following 2 weeks of red wine consumption. Data were analysed using the Minitab ${ }^{\text {TM }}$ statistical software package, version 4.0. (Minitab Inc., Addison-Wesley Publishng Co., Reading, MA, USA). The differences were considered statistically significant at $P \leq 0 \cdot 05$.

\section{Results}

Subjects were all healthy non-smokers. No statistically significant differences were observed in mean age (35 (SE 2.5) and 29 (SE 2.5) years), height (1.67 (SE 0.1) and 1.65 (SE 0.1) m), weight (68.3 (SE 1.9) and 67 (SE 3.2) kg) or BMI $\left(22.5(\right.$ SE 0.3$)$ and $\left.23.2(\operatorname{SE~} 1.2) \mathrm{kg} / \mathrm{m}^{2}\right)$ between the red wine and the control group, respectively. The red wine used in the study was a Bulgarian Young Vatted Cabernet Sauvignon. Its analysis by HPLC with tandem MS and diode array detection revealed the presence of a number of flavonoids and phenolic compounds, of which nineteen were identified and the daily intake of the volunteers quantified. The results obtained are illustrated in Fig. 1 and are summarised in Table 1.

Consumption of red wine was associated with a small but significant increase ( $P \leq 0 \cdot 05$, unpaired $t$ test) in total phenolic concentration in plasma. This was reflected by a $7 \%$ increase in plasma antioxidant capacity that failed to achieve statistical significance (Table 2). No change in plasma total phenolic concentration or antioxidant capacity was observed in the control group. There were no significant changes in the plasma concentrations of $\alpha$ - and $\gamma$-tocopherol, retinol and ascorbic acid. Similarly, no differences were observed between the groups in plasma concentrations of the individual carotenoids and data are therefore presented as total carotenoids in Table 2 .

The maximum concentration of conjugated dienes produced in $\mathrm{Cu}$-oxidised $\mathrm{LDL}$ was reduced significantly $(P=0.026$, paired $t$ test; Table 3$)$ in the red wine group after 2 weeks, as was the TBARS concentration in $\mathrm{Cu}$-oxidised LDL $(P=0 \cdot 050$, paired $t$ test; Table 3$)$. There were no significant changes observed in conjugated dienes or TBARS in the control group. There was a significant increase $(P=0.02$, paired $t$ test $)$ in the concentration of HDL cholesterol after 2 weeks in the red wine group while no change was observed in the control group. No significant change was observed in other fasting lipids or in homocysteine in either group (Table 3 ).

HPLC with tandem MS in the selective reaction monitoring mode detected trace amounts of flavan-3-ol glucuronides in the plasma of subjects from the red wine group post-intervention (Table 4). Peaks M-1 (retention time $\left(t_{\mathrm{R}}\right)=16.6 \mathrm{~min}$, absorbance maximum $\left.\left(\lambda_{\max }\right)=280 \mathrm{~nm}\right)$ and M-2 $\left(t_{\mathrm{R}}=23.0 \mathrm{~min}, \quad \lambda_{\max }=280 \mathrm{~nm}\right)$ both had $[\mathrm{M}-\mathrm{H}]^{-}$at $\mathrm{m} / \mathrm{z}$ 465, which yielded secondary MS $\left(\mathrm{MS}^{2}\right)$ fragments $(\mathrm{M}-176$, loss of a glucuronyl unit) 


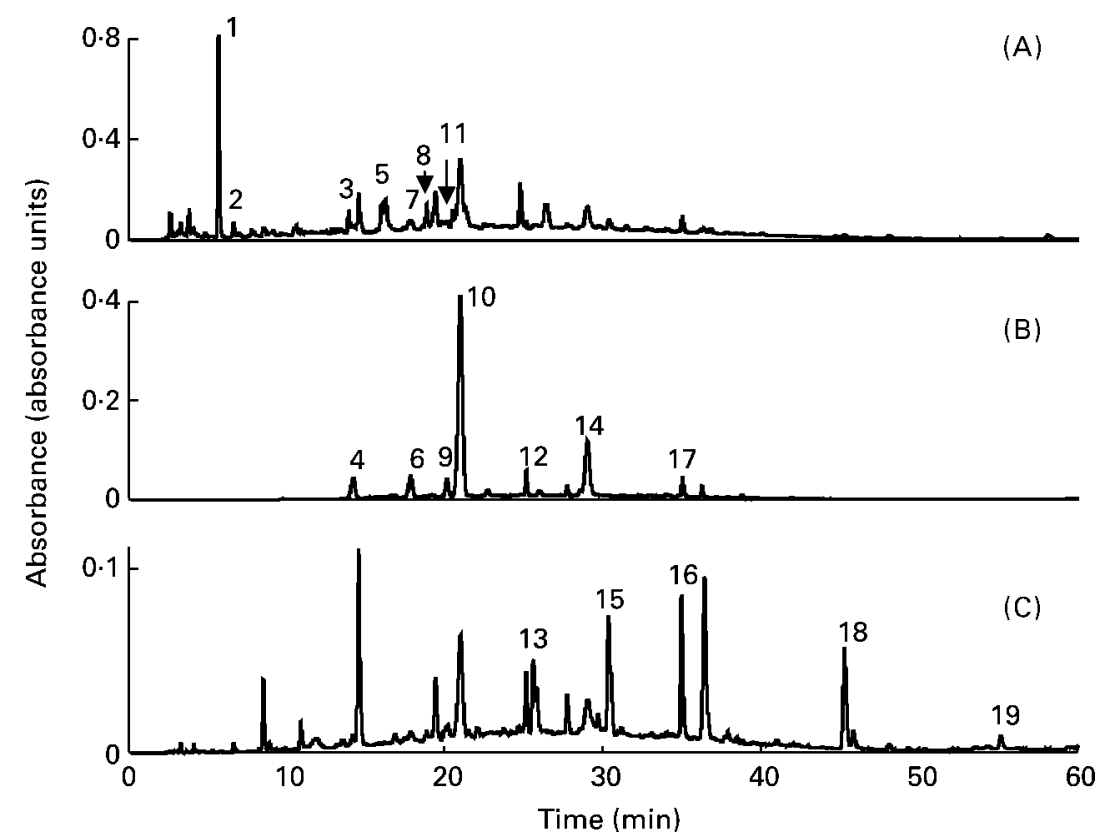

Fig. 1. Gradient HPLC chromatogram of phenolics in the Bulgarian Young Vatted Cabernet Sauvignon with diode array detector operating at $280 \mathrm{~nm}$ (trace A), $520 \mathrm{~nm}$ (trace B) and $365 \mathrm{~nm}$ (trace C) for the detection of flavan-3-ols, anthocyanins and flavonols, respectively. (For tandem MS data and identification and quantification of peaks 1-19, see Table 1.)

corresponding to $(+)$-catechin/(-)-epicatechin at $\mathrm{m} / \mathrm{z}, 289$ and 245. The $[\mathrm{M}-\mathrm{H}]^{-}-176$ loss is in keeping with the cleavage of a glucuronyl unit. The MS fragmentation pattern, together with the HPLC elution order, indicates that the earlier-eluting M-1 peak is a $(+)$-catechin glucuronide while M-2 is an (-)-epicatechin glucuronide. Peaks
M-3 $\quad\left(t_{\mathrm{R}}=21.6 \mathrm{~min}, \quad \lambda_{\max }=280 \mathrm{~nm}\right) \quad$ and $\quad \mathrm{M}-4$ $\left(t_{\mathrm{R}}=27.1 \mathrm{~min}, \quad \lambda_{\max }=280 \mathrm{~nm}\right)$ also had similar mass spectra, with $[\mathrm{M}-\mathrm{H}]^{-}$at $\mathrm{m} / z$, 479 which on loss of $176 \mathrm{amu}$ (loss of a glucuronyl unit) yielded an $\mathrm{MS}^{2}$ ion at $\mathrm{m} / \mathrm{z}$ 303. These fragments are 14 amu higher than the equivalent ions in the spectra of M-1 and M-2, indicating

Table 1. Identification of flavonoids and phenolic compounds in Young Vatted Bulgarian Cabernet Sauvignon red wine based on HPLC retention times $\left(t_{\mathrm{R}}\right)$, absorbance maximum $\left(\lambda_{\max }\right)$ and tandem MS data obtained in full-scan negative- and positive-ion modes*

(Amount ingested daily is mean value and standard error for three determinations)

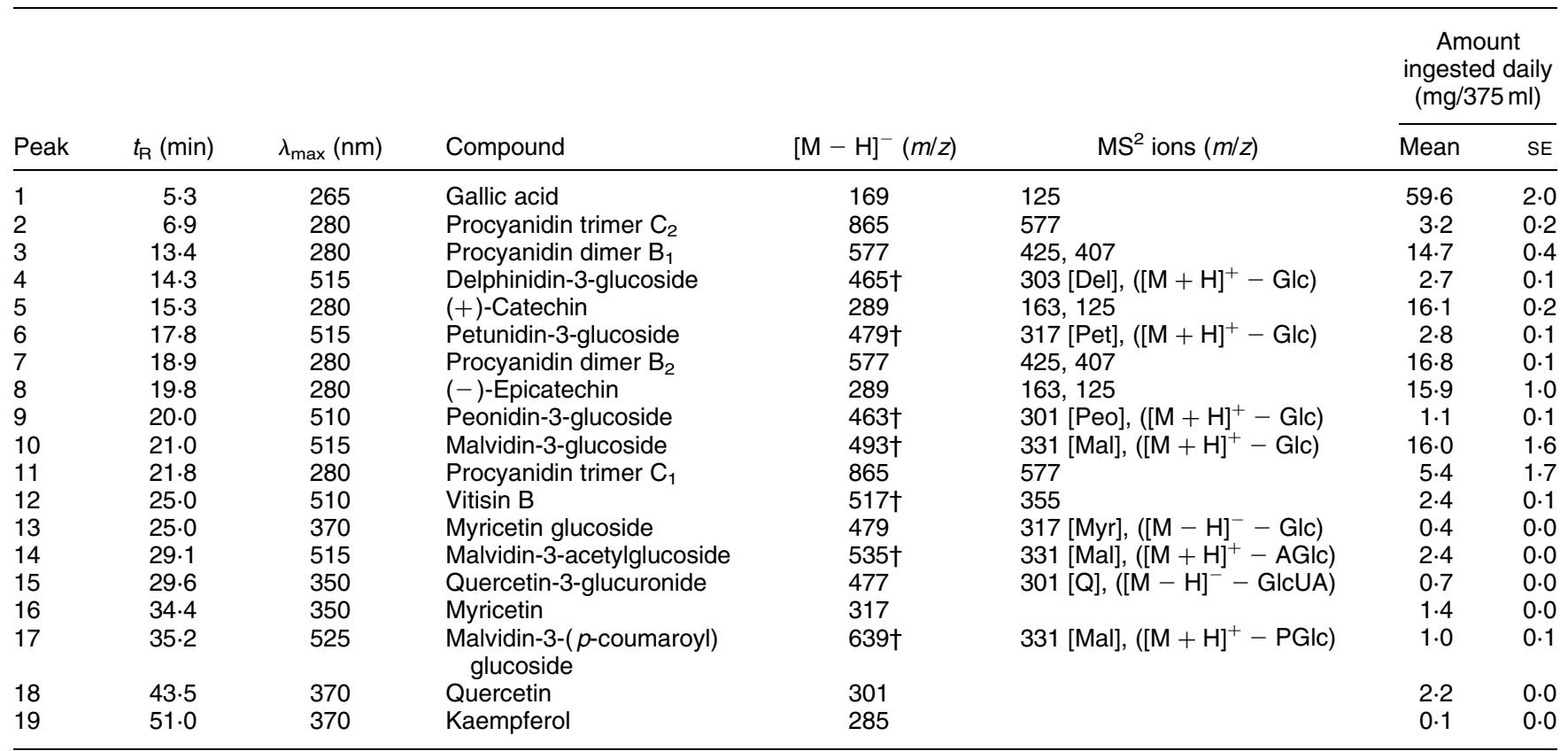

$[\mathrm{M}-\mathrm{H}]^{-}$, negatively charged molecular ion; $\mathrm{MS}^{2}$, secondary $\mathrm{MS}$; Del, delphinidin; $[\mathrm{M}+\mathrm{H}]^{+}$, positively charged molecular ion; Glc, glucosyl; Pet, petunidin; Peo, peonidin; Mal, malvidin; Myr, myricetin; AGlc, acetylglucosyl; Q, quercetin; GlcUA, glucuronyl; PGlc, $p$-coumaroylglucosyl.

* Peak numbers and $t_{\mathrm{R}}$ values refers to peaks in Fig. 1 .

†Positively charged molecular ion $\left([\mathrm{M}+\mathrm{H}]^{+}\right)$. 
Table 2. Antioxidant capacity, total phenolics, tocopherols, retinol, carotenoids and ascorbic acid content of plasma collected from human volunteers consuming $375 \mathrm{ml}$ red wine daily for a 2-week period $(n 12)$ and from a control group $(n 8)$ (Mean values and their standard errors)

\begin{tabular}{|c|c|c|c|c|c|c|c|c|}
\hline \multirow[b]{3}{*}{ Parameter } & \multicolumn{4}{|c|}{ Red wine group } & \multicolumn{4}{|c|}{ Control group } \\
\hline & \multicolumn{2}{|c|}{ Baseline } & \multicolumn{2}{|c|}{ After 2 weeks } & \multicolumn{2}{|c|}{ Baseline } & \multicolumn{2}{|c|}{ After 2 weeks } \\
\hline & Mean & SE & Mean & $\mathrm{SE}$ & Mean & $\overline{S E}$ & Mean & $\mathrm{SE}$ \\
\hline Antioxidant capacity (\% Fremy's radical reduced/l) & 37.4 & 2.5 & 40.5 & $3 \cdot 3$ & $35 \cdot 3$ & 1.8 & 34.0 & $2 \cdot 3$ \\
\hline Total phenolics ( $\mu \mathrm{mol} \mathrm{GAE} / \mathrm{l})$ & $12 \cdot 4$ & 5.9 & $16 \cdot 6^{\star \star} \dagger$ & 5.9 & 11.8 & 0.0 & $13 \cdot 0$ & $5 \cdot 9$ \\
\hline$\alpha$-Tocopherol $(\mu \mathrm{mol} / \mathrm{l})$ & 25.3 & 1.9 & $23 \cdot 2$ & 0.9 & 23.2 & 1.9 & 23.2 & 1.9 \\
\hline$\gamma$-Tocopherol $(\mu \mathrm{mol} / \mathrm{l})$ & 1.0 & 0.2 & 1.2 & 0.2 & 1.4 & 0.2 & 1.9 & 0.4 \\
\hline Retinol ( $\mu \mathrm{mol} / /)$ & $2 \cdot 4$ & 0.0 & $2 \cdot 1$ & $0 . \overline{3}$ & 1.8 & 0.3 & 1.8 & 0.3 \\
\hline Total carotenoids $(\mu \mathrm{mol} / \mathrm{l})$ & $1 \cdot 8$ & 0.2 & 1.4 & 0.2 & 1.7 & 0.0 & 1.4 & 0.0 \\
\hline Ascorbic acid $(\mu \mathrm{mol} / \mathrm{l})$ & 63.5 & $5 \cdot \overline{8}$ & $54 \cdot 3$ & 7.4 & 51.8 & 4.6 & 55.6 & 8.6 \\
\hline
\end{tabular}

GAE, gallic acid equivalents.

Statistically significant difference within each group based on paired $t$ test: ${ }^{*} P \leq 0.001$.

Statistically significant difference between intervention and control groups based on unpaired $t$ test: $\uparrow P \leq 0.05$.

Table 3. Maximum diene concentration, maximal oxidation rate and lag phase before rapid onset of conjugated diene production and thiobarbituric acid-reactive substances (TBARS) in copper-oxidised LDL, fasting plasma total, LDL and HDL cholesterol concentrations, fasting triacylglycerol (TAG) concentration and homocysteine level in plasma of human volunteers consuming $375 \mathrm{ml}$ red wine daily for 2 weeks $(n 12)$ and from a control group $(n 8)$

(Mean values and their standard errors)

\begin{tabular}{|c|c|c|c|c|c|c|c|c|}
\hline \multirow[b]{3}{*}{ Parameter } & \multicolumn{4}{|c|}{ Red wine group } & \multicolumn{4}{|c|}{ Control group } \\
\hline & \multicolumn{2}{|c|}{ Baseline } & \multicolumn{2}{|c|}{ After 2 weeks } & \multicolumn{2}{|c|}{ Baseline } & \multicolumn{2}{|c|}{ After 2 weeks } \\
\hline & Mean & SE & Mean & SE & Mean & SE & Mean & SE \\
\hline Maximum diene concentration (nmol/mg LDL protein) & 913 & 85 & $715^{\star}$ & 53 & 860 & 76 & 868 & 75 \\
\hline Maximal oxidation rate ( $\mathrm{nmol} / \mathrm{mg}$ LDL protein per min) & 9.4 & $1 \cdot 2$ & $7 \cdot 4$ & 0.6 & $9 \cdot 3$ & $2 \cdot 3$ & 8.4 & $0 \cdot 1$ \\
\hline Lag phase (min) & $43 \cdot 8$ & $3 \cdot 7$ & 49.8 & $2 \cdot 9$ & 44.3 & $6 \cdot 8$ & $46 \cdot 4$ & 7.5 \\
\hline TBARS (nmol/mg LDL protein) & $69 \cdot 0$ & $8 \cdot 3$ & $50 \cdot 6^{*}$ & $5 \cdot 6$ & 62.5 & $12 \cdot 6$ & $62 \cdot 4$ & $9 \cdot 1$ \\
\hline Total cholesterol (mmol/l) & 4.5 & 0.3 & 4.9 & 0.3 & $4 \cdot 2$ & 0.4 & $4 \cdot 1$ & 0.3 \\
\hline LDL cholesterol (mmol/l) & $2 \cdot 7$ & 0.2 & 2.9 & 0.2 & $2 \cdot 4$ & 0.3 & $2 \cdot 4$ & 0.3 \\
\hline HDL cholesterol (mmol/l) & 1.4 & 0.1 & $1.5^{\star}$ & 0.1 & 1.4 & 0.1 & 1.4 & 0.1 \\
\hline TAG (mmol/l) & 0.8 & $0 \cdot 1$ & 0.9 & $0 \cdot 1$ & 0.8 & 0.2 & 0.7 & 0.1 \\
\hline Homocysteine $(\mu \mathrm{mol} / \mathrm{l})$ & $8 \cdot 1$ & 0.8 & $7 \cdot 8$ & 0.7 & $9 \cdot 8$ & 0.7 & $10 \cdot 0$ & 1.0 \\
\hline
\end{tabular}

Statistically significant difference within each group based on paired $t$ test: ${ }^{*} P \leq 0.05$.

the presence of methylated flavan-3-ol glucuronides. M-3 is therefore probably a methyl catechin glucuronide and the later-eluting M-4 a methyl epicatechin glucuronide (Table 4). Without reference compounds it was not possible to determine the positions on the flavan-3-ol skeleton of the methyl and glucuronic acid substituents. The most likely candidates for M-2 and M-4 are (-)-epicatechin-3'-O-glucuronide and $4^{\prime}-O$-methyl-(-)-epicatechin$3^{\prime}-O$-glucuronide, which have been identified as the main metabolites in human plasma after ingestion of (-)-epicatechin. Other methylated and glucuronide conjugates of (-)-epicatechin were, however, also present, albeit in smaller amounts (Natsume et al. 2003). None of the four flavan-3-ol metabolites was detected in the plasma of subjects from the control group.

\section{Discussion}

There is a growing awareness of the potential health benefits of diets rich in fruits and vegetables and nutritional guidelines indicate that an increase in the consumption of foods rich in antioxidant nutrients may decrease the

Table 4. HPLC and mass spectral properties of metabolites detected in plasma of human volunteers after consuming $375 \mathrm{ml}$ red wine daily for a 2-week period

\begin{tabular}{lclcl}
\hline Peak & $t_{\mathrm{R}}(\mathrm{min})$ & Metabolite & {$[\mathrm{M}-\mathrm{H}]^{-}(\mathrm{m} / \mathrm{z})$} & \multicolumn{1}{c}{$\mathrm{MS}^{2}$ ions $(\mathrm{m} / \mathrm{z})$} \\
\hline M-1 & $16 \cdot 6$ & (+)-Catechin glucuronide & 465 & $289 ; 245\left(\mathrm{C} ;[\mathrm{M}-\mathrm{H}]^{-}-\mathrm{GlcUA}\right)$ \\
M-2 & $23 \cdot 0$ & (-)-Epicatechin glucuronide & 465 & $289 ; 245\left(\mathrm{EC} ;[\mathrm{M}-\mathrm{H}]^{-}-\mathrm{GlcUA}\right)$ \\
M-3 & 21.6 & Methyl catechin glucuronide & 479 & $303\left(\mathrm{MC} ;[\mathrm{M}-\mathrm{H}]^{-}-\mathrm{GlcUA}\right)$ \\
M-4 & $27 \cdot 1$ & Methyl epicatechin glucuronide & 479 & 303 (MEC; [M - H] $\left.]^{-}-\mathrm{GlcUA}\right)$ \\
\hline
\end{tabular}

$t_{\mathrm{R}}$, retention time; $[\mathrm{M}-\mathrm{H}]^{-}$, negatively charged molecular ion; $\mathrm{MS}^{2}$, secondary $\mathrm{MS} ; \mathrm{C},(+)$-catechin; GlcUA, glucuronyl unit; EC, (-)-epicatechin; MC, methyl catechin; MEC, methyl epicatechin. 
risk of CHD and certain cancers (The Scottish Office, 1993). Epidemiological studies have reported a reduction in the incidence of CHD with moderate daily red wine consumption, an anomaly referred to as the 'French paradox'. This effect has been ascribed to the low-molecular-weight phenolics in many plant-based foods, which can act as antioxidants because their extensive conjugated $\pi$-electron systems allow ready donation of electrons or hydrogen atoms from the hydroxyl moieties to free radicals (Scott, 1997).

In the present study, moderate daily consumption of red wine for 2 weeks resulted in a small but significant increase of $4.4 \mu \mathrm{mol}$ gallic acid equivalents/l in plasma total phenolics, which was associated with a non-significant increase in antioxidant capacity (Table 2). This is in contrast with several studies that have measured increases in both total phenols and plasma antioxidant activity at various times up to $24 \mathrm{~h}$ following the consumption of red wine (Maxwell et al. 1994; Whitehead et al. 1995; Day et al. 1997; Duthie et al. 1998; Serafini et al. 1998). However, in such studies the increases in plasma phenolics and antioxidant capacity begin to decline within $4 \mathrm{~h}$ of wine ingestion. In the present study, blood samples for the measurement of antioxidant capacity were taken in the morning, about $10-12 \mathrm{~h}$ after the consumption of red wine the previous evening, by which time the majority of the phenolics may have cleared from the blood. The data obtained indicate that regular red wine intake over 2 weeks does not lead to a sustained increase in total phenols in the circulation.

In the present study, there was a significant increase in the concentration of HDL cholesterol $(P \leq 0.05)$ in the red wine group post-intervention (Table 3 ). However, the change is small and unlikely to be of clinical significance.

There were no significant differences (unpaired $t$ tests) in the lag phase or any of the other indices of LDL oxidation between the red wine and control groups, post-intervention (Table 3). However, within the red wine group (paired $t$ test), there was a significant reduction in the maximum concentration of conjugated dienes $(P \leq 0 \cdot 05)$ and TBARS $(P \leq 0.05)$ post-intervention. While the lag phase was not increased significantly in the red wine group, there was an increase in eight of the twelve subjects. Our finding of a significant reduction in the concentration of conjugated dienes and TBARS without a statistically significant increase in the lag phase could lead one to suspect that there had been changes in LDL particle fatty acid composition. However, while we did not measure the LDL fatty acid composition, analysis using a computerised version of the food composition tables (Holland et al. 1991) of the subjects' daily diet records for the period of the trial revealed no significant changes in either the quantity or the quality of dietary fat intake. It is very unlikely, therefore, that the fat composition of the LDL particle was altered for eight of the twelve subjects and the four who responded differently were distinct in this respect. Thus, while there was not a statistically significant reduction in susceptibility of LDL to oxidation compared with the control group, changes within the red wine group appear to show some protection against LDL oxidation. This is mostly likely to be due to the small but statistically significant increase in the plasma concentration of phenolics, which can bind to LDL and offer protection against LDL oxidation. We speculate that the difference in response was simply due to person-to-person variation in response to the red wine intervention, as individuals may react differently to supplementation as has been suggested by Howard et al. (2002). Furthermore, the four subjects who did not show an increase in the lag phase did not respond differently in their plasma phenolic concentrations, TBARS or the maximum concentration and the rate of conjugated dienes, leading us to the conclusion that compliance to the intervention was met.

Although there was a trend towards a reduction in the plasma concentration of homocysteine in the red wine group, the results were not statistically significant (Table 3). Elevated circulating homocysteine level is associated with an increased risk of CVD (Refsum et al. 1998) and is affected by diet, mainly due to inadequate intakes of folate and vitamin $B_{12}$. There is evidence that a light to moderate consumption of alcohol is associated with lower fasting plasma concentrations of homocysteine; this has previously been reported for beer (van der Gaag et al. 2002) and red wine (Dixon et al. 2002). Although beer contains folate and vitamin $\mathrm{B}_{6}$, red wine contains negligible amounts of vitamin $\mathrm{B}_{6}$, and it is unlikely that these micronutrients alone can explain the beneficial effect.

Glucuronides of (+)-catechin and (-)-epicatechin and their methylated analogues were identified in plasma from the red wine group post-intervention (Table 4). However, the amounts present could not be quantified and are clearly not sufficient to make a significant contribution to the increased levels of phenolics detected in plasma after red wine consumption (Table 2). The presence of the flavan-3-ol metabolites is, however, in line with the findings of a previous study in which, following consumption of a single serving of $120 \mathrm{ml}$ red wine by human volunteers, $(+)$-catechin was detected in plasma after treatment with $\beta$-glucuronidase and arylsulphatase (Bell et al. 2000).

Two previous studies (Fuhrman et al. 1996; Nigdikar et al. 1998) have shown a reduction in LDL oxidation using similar doses of red wine $(375 \mathrm{ml} / \mathrm{d}$ and $400 \mathrm{ml} / \mathrm{d}$, respectively) and intervention periods ( 2 weeks) as the current study. However, there are a number of possible reasons to explain this apparent discrepancy. The phenolic composition of the wine used in wine trials is important with regard to its effect on LDL oxidation (Howard et al. 2002). In the present study, a Young Vatted Bulgarian Cabernet Sauvignon was used and the intake of phenolic compounds from the $375 \mathrm{ml}$ serving was $165 \mathrm{mg} / \mathrm{d}$, with the majority of the phenolics derived from anthocyanins, gallic acid and total flavan-3-ols (Table 1). The overall levels of phenolics in the wines used in the studies of Nigdikar et al. (1998) and Fuhrman et al. (1996) were somewhat higher than in the present study; for example, the amount of red wine phenolics ingested in the study of Nigdikar et al. (1998) was $248 \mathrm{mg} / \mathrm{d}$ in a $375 \mathrm{ml}$ serving. This difference in dose may explain why we observed no statistically significant effect on LDL oxidation.

A further consideration is that in the studies of Nigdikar et al. (1998) and Fuhrman et al. (1996) the LDL oxidation assays were carried out on fresh plasma samples. In our investigation EDTA-treated plasma was stored at $-80^{\circ} \mathrm{C}$ for several weeks prior to being assayed. Our experience (Higgins et al. 2001), along with that of Esterbauer et al. 
(1991) and Kleinveld et al. (1992), is that this does not adversely affect the reliability of the LDL oxidation assay. Another difference between the present investigation and the studies of Nigdikar et al. (1998) and Fuhrman et al. (1996) is that in both these studies the volunteers were male, while both male and female volunteers participated in the present study. This could have increased the interindividual variability in the response to the red wine intervention, making it more difficult to see a statistically significant difference in the lag phase between the intervention and control groups.

Although the red wine used in the present study contained a substantial amount of anthocyanins, particularly malvidin3-glucoside (Table 1), no anthocyanins were detected in plasma despite a thorough search using HPLC with tandem MS. This is in keeping with the findings of other human studies where reported urinary recoveries of anthocyanins after consumption of red wine, or anthocyanin-rich produce, typically range from 0.05 to $0.11 \%$ of intake (Frank et al. 2003; McGhie et al. 2003). Similarly, very low plasma anthocyanin concentrations have been reported in man (Cao \& Prior, 1999) and frequently the levels are below the limits of detection (Wu et al. 2002; Felgines et al. 2003). It is unclear at this juncture whether anthocyanins enter the circulatory system in trace amounts or whether they are absorbed in more substantial quantities and rapidly removed from the bloodstream.

Likewise, although the red wine contained a high level of gallic acid, despite a thorough search no gallic acid or metabolites of gallic acid were detected in the plasma of volunteers who consumed red wine.

In summary, a moderate consumption, over a 2-week period, of a red wine rich in gallic acid, flavan-3-ols and anthocyanins significantly increased the concentration of total phenolics in the plasma of human volunteers. This small increase may be due to the trace levels of glucuronide and methylated metabolites of flavan-3-ol monomers that were detected in plasma after red wine consumption. There were significant reductions in conjugated dienes and TBARS and a significant and modest increase in HDL cholesterol in the group supplemented with red wine. The findings from this study support the protective effects of red wine reported from previous epidemiological studies and current medical opinion that moderate daily intake of red wine may reduce the risk of developing CHD.

\section{Acknowledgements}

We thank all volunteers who participated in the study and the Department of Pathological Biochemistry, University of Glasgow, UK for use of their facilities. G.G.D. and S.J.D. are grateful to SEERAD for financial support. We thank Dr Pierre-Louis Teissedre (University of Montpellier, France) for supplying standards of procyanidin dimers. C.T. was supported by a BBSRC CASE postgraduate studentship with Safeway Stores plc.

\section{References}

Albert CM, Manson JE, Cook NR, Ajani UA, Gaziano JM \&
Hennekens CH (1999) Moderate alcohol consumption and the risk of sudden death among US male physicians. Circulation 100, 944-950.

Bell JR, Donovan JL, Wong R, Waterhouse AL, German JB, Walzem RL \& Kasim-Karakas SE (2000) (+)-Catechin in human plasma after ingestion of a single serving of reconstituted red wine. Am J Clin Nutr 71, 103-108.

Buege JA \& Aust SD (1978) Microsomal lipid peroxidation. Methods Enzymol 52, 302-310.

Burns J, Gardner PT, O’Neil J, et al. (2000) Relationship among antioxidant activity, vasodilation capacity, and phenolic content of red wines. J Agric Food Chem 48, 220-230.

Burns J, Crozier A \& Lean MEJ (2001a) Alcohol consumption and mortality: is red wine different to other alcoholic beverages? Nutr Metab Cardiovasc Dis 11, 249-258.

Burns J, Gardner PT, Matthews D, Duthie GG, Lean MEJ \& Crozier A (2001b) Extraction of phenolics and changes in antioxidant activity of red wine during vinification. J Agric Food Chem 49, 5797-5808.

Cao G \& Prior RL (1999) Anthocyanins are detected in human plasma after oral administration of an elderberry extract. Clin Chem 45, 574-576.

Criqui MH \& Ringel BL (1994) Does diet or alcohol explain the French paradox? Lancet 344, 1719-1723.

Day AJ, Mellon F, Barron D, Sarrazin G, Morgan MR \& Williamson G (2001) Human metabolism of dietary flavonoids: identification of plasma metabolites of quercetin. Free Radic Res 35, 941-952.

Day AP, Kemp HJ, Bolton C, Hartog M \& Stansbie D (1997) Effect of concentrated red grape juice consumption on serum antioxidant capacity and low-density lipoprotein oxidation. Ann Nutr Metab 41, 353-357.

Dixon JB, Dixon ME \& O'Brien PE (2002) Reduced plasma homocysteine in obese red wine consumers: a potential contributor to reduced cardiovascular risk status. Eur J Clin Nutr 56, 608-614.

Duthie GG (1999) Determination of activity of antioxidants in human subjects. Proc Nutr Soc 58, 1015-1024.

Duthie GG \& Crozier A (2003) Beverages. In Plants: Diet and Health, pp. 147-182 [G Goldberg, editor]. London: British Nutrition Foundation/Chapman Hall.

Duthie GG, Pedersen MW, Gardner PT, Morrice PC, Jenkinson AM, McPhail DB \& Steele GM (1998) The effect of whiskey and wine consumption on total phenol content and antioxidant capacity of plasma from healthy volunteers. Eur J Clin Nutr 52, 733-736.

Duthie SJ, Whalley LJ, Collins AR, Leaper S, Berger K \& Deary IJ (2002) Homocysteine, B-vitamin status, and cognitive function in the elderly. Am J Clin Nutr 75, 900-913.

Esterbauer H, Dieber-Rotheneder M, Striegl G \& Waeg G (1991) Role of vitamin $\mathrm{E}$ in preventing the oxidation of low-density lipoprotein. Am J Clin Nutr 53, 314-321.

Felgines C, Talavéra S, Gonthier M-P, Texier O, Scalbert A, Lamaison JL \& Remesy C (2003) Strawberry anthocyanins are recovered in urine as glucuro- and sulfoconjugates in humans. J Nutr 133, 1296-1301.

Frank T, Netzel M, Strass G, Bitsch R \& Bitsch I (2003) Bioavailability of anthocyanin-3- glucosides following consumption of red wine and red grape juice. Can J Physiol Pharmacol 81, 423-435.

Frankel EN, Waterhouse AL \& Teissedre PL (1995) Principal phenolic phytochemicals in selected Californian wines and their antioxidant activity in inhibiting oxidation of human low-density lipoproteins. J Agric Food Chem 43, 1165-1169.

Friedewald WT, Levy RI \& Fredrickson DS (1972) Estimation of the concentration of low-density lipoprotein cholesterol in plasma, without the use of the preparative ultracentrifuge. Clin Chem 18, 499-502. 
Fuhrman B, Lavy A \& Aviram M (1996) Consumption of red wine with meals reduces the susceptibility of human plasma and low-density lipoprotein to undergo lipid peroxidation. $A m$ $J$ Clin Nutr 63, 403-404.

Gardner PT, McPhail DB \& Duthie GG (1998) Electron spin resonance spectroscopic assessment of the antioxidant potential of teas in aqueous and organic media. $J$ Sci Food Agric 76, 257-262.

Goldberg DM, Tsang E, Karumanchiri A \& Soleas GJ (1998) Catechin and epicatechin concentrations of red wines: regional and cultivar related differences. Am J Enol Vitol 49, 23-34.

Hess D, Keller HE, Oberlin B, Bonfanti R \& Schuep W (1991) HPLC determination of carotenoids, tocopherols and retinol in plasma. Int J Vitam Nutr Res 61, 232-238.

Higgins S, Carroll YL, McCarthy SN, Corridan BM, Roche HM, Wallace JM, O'Brien NM \& Morrissey PA (2001) Susceptibility of LDL to oxidative modification in healthy volunteers supplemented with low doses of $n-3$ polyunsaturated fatty acids. Br J Nutr 85, 23-31.

Holland B, Welch AA, Unwin ID, Buss DH, Paul AA \& Southgate DAT (1991) McCance \& Widdowson's The Composition of Foods. Cambridge: Royal Society of Chemistry/Ministry of Agriculture, Fisheries and Food.

Howard A, Chopra M, Thurnham DI, Strain JJ, Fuhrman B \& Aviram M (2002) Red wine consumption and inhibition of LDL oxidation: what are the important components? Med Hypotheses 59, 101-104.

Kanner J, Frankel E, Granit R, German B \& Kinsella JE (1994) Natural antioxidants in grapes and wine. J Agric Food Chem 42, 64-69.

Kleinveld HA, Hak-Lemmers HLM, Stalenhoef AFH \& Demacker PNM (1992) Improved measurement of low-density lipoprotein susceptibility to copper-induced oxidation: application of a short procedure for isolating low-density lipoprotein. Clin Chem 38, 2066-2072.

Landrault N, Poucheret P, Ravel P, Cros G \& Teissedre PL (2001) Antioxidant capacities and phenolic levels of French wines from different varieties and vintages. J Agric Food Chem 49, 3341-3348.

McGhie TK, Ainge GD, Barnett LE, Cooney JM \& Jensen DJ (2003) Anthocyanin glycosides from berry fruit are absorbed and excreted unmetabolised by both humans and rats. J Agric Food Chem 51, 4532-4538.

Markwell MAK, Haas SM, Tolbert NE \& Bieber LL (1981) Protein determination in membrane and lipoprotein samples: manual and automated procedures. Methods Enzymol 72, 296-298.

Maxwell S, Cruickshank A \& Thorpe G (1994) Red wine and antioxidant activity in serum. Lancet 344, 193-194.

Natella F, Ghiselli A, Guidi A, Ursini F \& Scaccini C (2001) Red wine mitigates the postprandial increase of LDL susceptibility to oxidation. Free Radic Biol Med 30, 1036-1044.

Natsume M, Osakabe N, Oyama M, Sasaki M, Baba S, Nakamura Y, Osawa T \& Terao J (2003) Structures of (-)-epicatechin glucuronide identified from plasma and urine after oral ingestion of (-)-epicatechin: differences between human and rat. Free Radic Biol Med 34, 840-849.

Nigdikar SV, Williams NR, Griffin BA \& Howard AN (1998) Consumption of red wine polyphenols reduces the suscepti- bility of low-density lipoproteins to oxidation in vivo. Am J Clin Nutr 68, 258-265.

Refsum H, Ueland PM, Nygard O \& Vollset SE (1998) Homocysteine and cardiovascular disease. Annu Rev Med 49, 31-62.

Renaud S \& De Logeril M (1993) Wine, alcohol, platelets and the French paradox for coronary heart disease. Lancet 342, 1007-1011.

Rimm EB, Klatsky AL, Grobbee D \& Stampfer MJ (1996) Review of moderate alcohol consumption and reduced risk of coronary heart disease: is the effect due to beer, wine or spirits? Br Med J 312, 731-736.

Ross MA (1994) Determination of ascorbic acid and uric acid in plasma by high-performance liquid chromatography. J Chromatogr B 657, 197-200.

Saltmarsh M, Crozier A \& Radcliffe B (2003) Fruit and vegetables. In Plants: Diet and Health, pp. 107-133 [G Goldberg, editor]. London: British Nutrition Foundation/Chapman Hall.

Santos-Buelga C, Francia-Aricha EM \& Escribano-Bailón MT (1995) Comparative flavan-3-ol composition of seeds from different grape varieties. Food Chem 53, 197-201.

Scott G (1997) Antioxidants in Science, Technology, Medicine and Nutrition. Chichester, UK: Albion Publishing.

Serafini M, Maiani G \& Ferro-Luzzi A (1998) Alcohol-free red wine enhances plasma antioxidant capacity in humans. $J$ Nutr 128, 1003-1007.

Singleton VL (1982) Grape phenolics: backgrounds and prospects. In Proceedings of the University of California, Davis, Grape and Wine Centennial Symposium, pp. 215-222 [AD Webb, editor]. Davis, CA: University of California Press.

Singleton VL \& Rossi JA (1965) Colorimetry of total phenolics with phosphomolybdic-phosphotungstic reagents. Am J Enol Vitol 16, 144-158.

Swaine T \& Hillis E (1959) The phenolic constituents of Prunus domestica I. The quantitative analysis of phenolic constituents. J Sci Food Agric 10, 63-68.

Teissedre PL, Frankel EN, Waterhouse AL, Peleg H \& German JB (1996) Inhibition of in vitro human LDL oxidation by phenolic antioxidants from grapes and wines. J Sci Food Agric 70, $55-61$.

The Scottish Office (1993) Report of a Working Party to the Chief Medical Officer for Scotland. Edinburgh: The Scottish Office Home and Health Department.

van der Gaag MS, Ubbink JB, Sillanaukee P, Nikkari S \& Hendriks HF (2002) Effect of consumption of red wine, spirits and beer on serum homocysteine. Lancet 355, 1522.

van Golde PHM, Sloots LM \& Vermeulen WP (1999) The role of alcohol in the anti low-density lipoprotein oxidation activity of red wine. Atherosclerosis 147, 365-370.

Vinson JA \& Hontz BA (1995) Phenol antioxidant index of comparative antioxidant effectiveness of red and white wines. $J$ Agric Food Chem 43, 401-403.

Whitehead TP, Robinson D, Allaway S, Syms J \& Hale A (1995) Effect of red wine ingestion on the antioxidant capacity of serum. Clin Chem 41, 32-35.

Wu X, Cao G \& Prior RL (2002) Absorpton and metabolism of anthocyanis in elderly women after consumption of elderberry or blueberry. J Nutr 132, 1865-1871. 